\title{
Impact of deposition parameters on the material quality of SPC poly-Si thin films using high-rate PECVD of a-Si:H
}

\author{
Avishek Kumar ${ }^{1,2,3, a}$, Per Ingemar Widenborg ${ }^{1}$, Goutam Kumar Dalapati ${ }^{3}$, \\ Gomathy Sandhya Subramanian ${ }^{3}$, and Armin Gerhard Aberle ${ }^{1,2}$ \\ 1 Solar Energy Research Institute of Singapore, National University of Singapore, 7 Engineering Drive 1, \\ 117574 Singapore, Singapore \\ 2 Department of Electrical and Computer Engineering, National University of Singapore, 117583 Singapore, Singapore \\ 3 Institute of Materials Research and Engineering, A*STAR (Agency for Science, Technology and Research), \\ 3 Research Link, 117602 Singapore, Singapore
}

Received: 23 September 2014 / Received in final form: 12 March 2015 / Accepted: 4 May 2015 Published online: 27 May 2015

(C) Kumar et al., published by EDP Sciences, 2015

\begin{abstract}
The impact of the deposition parameters such as gas flow (sccm) and RF plasma power density $\left(\mathrm{W} / \mathrm{cm}^{2}\right)$ on the deposition rate of a-Si:H films is systematically investigated. A high deposition rate of up to $146 \mathrm{~nm} / \mathrm{min}$ at $13.56 \mathrm{MHz}$ is achieved for the a-Si:H films deposited with high lateral uniformity on $30 \times 40 \mathrm{~cm}^{2}$ large-area glass substrates. A relationship between the $\mathrm{SiH}_{4}$ gas flow and the $\mathrm{RF}$ power density is established. The $\mathrm{SiH}_{4}$ gas flow to RF power density ratio of about $2.4 \mathrm{sccm} / \mathrm{mW} \mathrm{cm}^{-2}$ is found to give a linear increase in the deposition rate. The influence of the deposition rate on the material quality is studied using UV-VIS-NIR spectrophotometer and Raman characterisation techniques. Poly-Si thin film with crystal quality as high as $90 \%$ of single-crystalline Si wafer is obtained from the SPC of high rate deposited a-Si:H films.
\end{abstract}

\section{Introduction}

SPC poly-Si thin-film material is a promising semiconductor for the PV industry, combining the robustness of c-Si with the advantages of the thin-film approach [1]. SPC poly-Si thin films are obtained from the annealing of a-Si:H films in a $\mathrm{N}_{2}$ atmosphere for $12 \mathrm{~h}$ at $610{ }^{\circ} \mathrm{C}$ [2]. Plasma-enhanced chemical vapour deposition (PECVD) is widely used in industry for large-area deposition of a-Si:H films. However, the low deposition rate of a-Si:H films $(25-35 \mathrm{~nm} / \mathrm{min})$ in traditional PECVD processes significantly adds to the cost of poly-Si thin-film solar cells [3]. There are other deposition techniques such as e-beam evaporation and hot wire chemical vapour deposition (HWCVD) which are capable of a-Si:H film depositions at a very high rate $(\gg 100 \mathrm{~nm} / \mathrm{min})$. However, the electronic properties of SPC poly-Si films obtained by these deposition techniques are inferior to those obtained from PECVD, which makes them difficult to commercialise. The a-Si films deposited by the e-beam evaporation technique have a high degree of thickness non-uniformity over large areas, which leads to problems at the device level (such as laterally non-uniform short-circuit current

\footnotetext{
${ }^{a}$ e-mail: avishek.kumar@nus.edu.sg
}

densities of solar cells, or pinholes and cracks that are detrimental to the solar cell performance [4]). On the other hand, a-Si:H films deposited by HWCVD have a very high nucleation rate, leading to SPC poly-Si films with much smaller grains compared with films deposited by PECVD [5].

Some results on a-Si:H films deposited with the high-rate PECVD technique can be found in the literature [6-11]. However, most of these deposited films suffered from internal stress, large microvoids and high dangling bond densities. The possible reason for this could be the fact that the substrate temperature $\left(T_{s}\right)$ used for these a-Si:H depositions was restricted to below $250{ }^{\circ} \mathrm{C}$. Recently, Jin [12] demonstrated in his doctoral thesis that an increase in the substrate temperature to $400{ }^{\circ} \mathrm{C}$ yields a high-quality poly-Si film prepared from the SPC of an a-Si:H film deposited at significantly higher rate using PECVD. The performance of the poly-Si thin-film solar cell obtained from the SPC of a-Si:H films deposited at high rate was also found to be comparable to that of the standard low-rate deposited cells [12]. In addition, it was shown that there was a decrease in the contamination level in the absorber layer when the a-Si:H film deposition rate was increased [12]. In a traditional PECVD, 
contaminants such as carbon (C), nitrogen (N) and oxygen $(\mathrm{O})$ are controlled in the a-Si:H films by keeping the base deposition pressure extremely low in the range of $10^{-8}$ Torr. This is generally achieved by the use of expensive turbo pumps. Thus, by controlling the contaminants, high-rate PECVD provides the flexibility to deposit at higher base pressure. This makes high-rate PECVD very interesting for large-scale industrial applications where the use of expensive turbo pumps is often not economical. In addition, a much thicker absorber layer is possible through the use of high-rate deposition, which otherwise is virtually impossible with a low deposition rate $(<35 \mathrm{~nm} / \mathrm{min})$. A thicker absorber layer is required to enhance the current of poly-Si thin-film solar cells, and hence their PV efficiency. Furthermore, the electronic properties of a SPC poly-Si thin film largely depend on the post-deposition treatments, which gives us the possibility to extensively explore the process parameter space of a-Si:H deposition for SPC poly-Si thin-film solar cell applications far beyond of what has been investigated for the a-Si:H solar cell field.

In this paper, we investigate the effects of the main deposition parameters ( $\mathrm{RF}$ power density $\left(\mathrm{mW} / \mathrm{cm}^{2}\right), \mathrm{SiH}_{4}$ gas flow (sccm), process pressure, etc.) on the deposition rate and thickness uniformity of a-Si:H films deposited on $30 \times 40 \mathrm{~cm}^{2}$ large-area glass substrates. Furthermore, the paper presents a detailed study about the impact of the deposition parameters of the a-Si:H films on the structural quality of the resulting SPC poly-Si films. A high deposition rate of up to $146 \mathrm{~nm} / \mathrm{min}$ at $13.56 \mathrm{MHz}$ is achieved for the a-Si:H films deposited with high lateral uniformity on $30 \times 40 \mathrm{~cm}^{2}$ large-area glass substrates.

\section{Experimental details}

An $\sim 70 \mathrm{~nm}$ thick $\mathrm{SiN}_{x}$ barrier coating was deposited onto $300 \times 400 \times 3.3 \mathrm{~mm}^{3}$ planar glass sheets (Schott, Borofloat) in a PECVD chamber (MVSystems, USA) at a temperature $\sim 460{ }^{\circ} \mathrm{C}$. The $\mathrm{SiN}_{x}$ film acts as an antireflection coating as well as a diffusion barrier for impurities in the glass substrate. The $\mathrm{SiN}_{x}$ coated glass was then loaded into a special PECVD chamber with an electrode spacing of $23 \mathrm{~mm}$. The a-Si:H films were then deposited using different combinations of $\mathrm{SiH}_{4}$ gas flow rate and $\mathrm{RF}$ power density, at the conventional plasma generation frequency of $13.56 \mathrm{MHz}$. The complete recipe used to deposit a-Si:H films is summarised in Table 1. The deposited a-Si:H films were then annealed (Nabertherm, N 120/65HAC furnace, Germany) at $610{ }^{\circ} \mathrm{C}$ in a $\mathrm{N}_{2}$ atmosphere for a duration of $12 \mathrm{~h}$ to achieve solid phase crystallisation of the film. A rapid thermal anneal (RTA, CVD Equipment, USA) for 1 minute at a peak temperature of $1000{ }^{\circ} \mathrm{C}$ in $\mathrm{N}_{2}$ atmosphere was then used to remove crystallographic defects from the SPC poly-Si thin-films and to activate the dopants. Each $30 \times 40 \mathrm{~cm}^{2}$ poly-Si coated glass sheet was then cut into 12 equal small pieces of size $10 \times 10 \mathrm{~cm}^{2}$. Optical reflectance measurements in the 250-1500 nm wavelength range were performed on each of the 12 pieces of the poly-Si film using an UV-VIS-NIR spectrophotometer (PerkinElmer, Lambda 950, UV/VIS Spectrometer). The
Table 1. Experimental details used for the PECVD of the $p^{-}$ a-Si:H films.

\begin{tabular}{cc}
\hline Process condition & $p^{-}$a-Si layer \\
\hline $\mathrm{SiH}_{4}(\mathrm{sccm})$ & $60-400$ \\
$100 \mathrm{ppm} \mathrm{B}_{2} \mathrm{H}_{6}: \mathrm{H}_{2}(\mathrm{sccm})$ & 0.2 \\
Substrate temperature $\left({ }^{\circ} \mathrm{C}\right)$ & 380 \\
Pressure $(\mathrm{Pa})$ & 107 \\
Time $(\mathrm{min})$ & $5-20$ \\
\hline
\end{tabular}

thickness of the poly-Si thin film was then calculated by curve fitting of the reflectance data with an optical simulation programme (WVASE). The thickness uniformity of the poly-Si thin film over the $30 \times 40 \mathrm{~cm}^{2}$ glass sheet was determined by calculating the thickness of each of the 12 pieces of the poly-Si film obtained from the glass sheet. The thicknesses of selected a-Si:H samples were also determined by ellipsometry and were found to be in good agreement with the thickness data of the poly-Si films obtained from WVASE. The deposition rate was then obtained by dividing the average thickness of the poly-Si film by the deposition time. Finally, the material quality of the poly-Si thin film was determined using UV reflectance measurements [13-15] and Raman spectroscopy [16, 17] measurements (Witec Alpha 300R confocal Raman microscope equipped with a $532 \mathrm{~nm} \mathrm{Nd:YAG} \mathrm{lase),} \mathrm{whereby}$ the samples were always measured from the air side.

\section{Results and discussion}

\subsection{Effect of $\mathrm{SiH}_{4}$ gas flow rate and RF power density on the deposition rate of $\mathrm{a}-\mathrm{Si}: \mathrm{H}$ films}

Figure 1 shows the deposition rate of a-Si:H films as a function of the $\mathrm{SiH}_{4}$ gas flow rate. The plasma power density, process pressure and the substrate temperature were kept constant at $67 \mathrm{~mW} / \mathrm{cm}^{2}, 107 \mathrm{~Pa}$ and $\sim 380{ }^{\circ} \mathrm{C}$, respectively, while the $\mathrm{SiH}_{4}$ gas flow rate was systematically increased. It can be clearly seen that the deposition rate of the a-Si:H films increases from 17 to $75 \mathrm{~nm} / \mathrm{min}$ when the $\mathrm{SiH}_{4}$ gas flow rate is increased from 60 to $225 \mathrm{sccm}$. Detailed observation of figure 1 reveals that the deposition rate approaches to a saturation value when the $\mathrm{SiH}_{4}$ gas flow rate is increased beyond about $200 \mathrm{sccm}$. The saturation in deposition rate at high $\mathrm{SiH}_{4}$ gas flows could be from the limitation of plasma power density to ionize the gas present in the chamber. Thus, further experiments were carried out to understand the effect of the plasma power density on the deposition rate of a-Si:H films at high $\mathrm{SiH}_{4}$ gas flow rate.

Figure 2 shows the deposition rate of a-Si:H films as a function of the RF plasma power density. $\mathrm{The}_{\mathrm{SiH}}$ gas flow rate, process pressure and the substrate temperature were kept constant at $200 \mathrm{sccm}, 107 \mathrm{~Pa}$ and $\sim 380{ }^{\circ} \mathrm{C}$, respectively, while the plasma power density was systematically increased. At $200 \mathrm{sccm}$ of $\mathrm{SiH}_{4}$ gas flow, there is a significant increase in the a-Si:H deposition rate from 71 to $93 \mathrm{~nm} / \mathrm{min}$ when the plasma power density is increased from 67 to $100 \mathrm{~mW} / \mathrm{cm}^{2}$. The a-Si:H deposition 


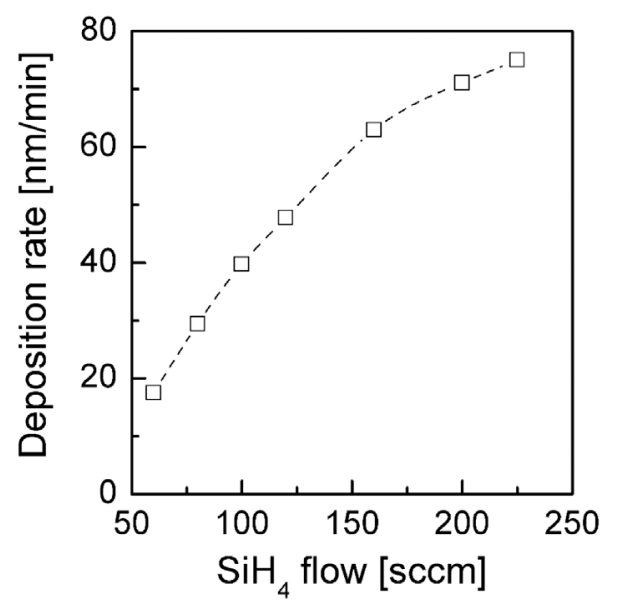

Fig. 1. Deposition rate of a-Si:H films as a function of $\mathrm{SiH}_{4}$ flow.

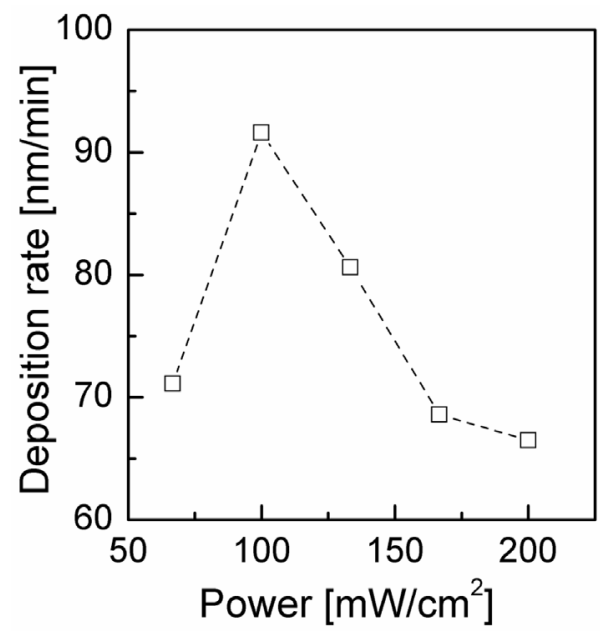

Fig. 2. Deposition rate of a-Si:H films as a function of the RF power density. The dotted lines are guides to the eye.

rate then decreases with a further increase of the plasma power density. It seems that the further increase of the plasma power density led to the saturation of the active species (responsible for the deposition rate) present in the plasma region at $200 \mathrm{sccm}$ of $\mathrm{SiH}_{4}$ gas flow rate [18]. In addition, the increase in the plasma power density also results in the formation of dust or small particles [18]. The combined effects of dust generation and saturation of the active species (positive ions) might be responsible for the decrease in the a-Si:H deposition rate. Furthermore, the dust particles generated at high power density plasma get accumulated and form a sheath near the throttle valve connected to the pump. This accumulated layer of dust particles impacts the flow of gas in the chamber, which also causes a laterally more non-uniform deposition (to be discussed in detail in Sect. 3.2). From the above discussion, it was observed that the increase in the deposition rate cannot be sustained by adjusting the power and gas flow rate individually. It is thus, desired to establish a relationship between the RF power density and the $\mathrm{SiH}_{4}$ gas flow rate to have a sustained growth rate of the a-Si:H

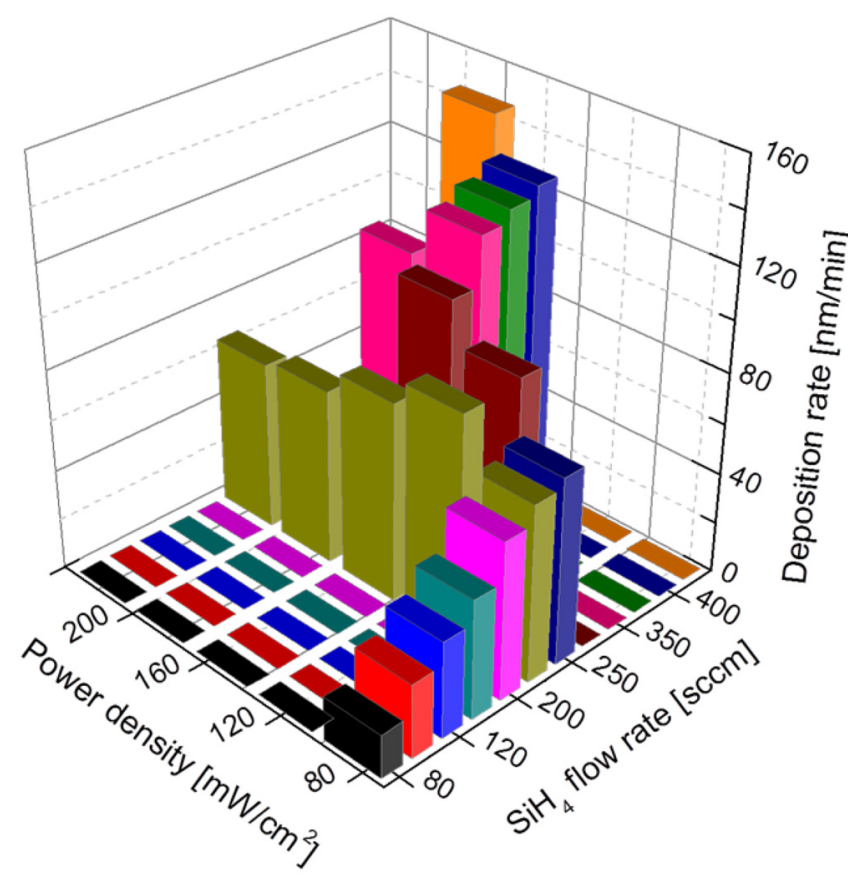

Fig. 3. Deposition rate of the a-Si:H films as a combined function of the plasma power and the $\mathrm{SiH}_{4}$ flow rate.

films. Further experiments were carried out to study the combined effect of the plasma power density and the $\mathrm{SiH}_{4}$ gas flow rate on the deposition rate of the a-Si:H films. Figure 3 shows the a-Si:H deposition rate as a combined function of the $\mathrm{SiH}_{4}$ gas flow rate and the RF plasma power density. From Figure 3 it can be clearly seen that, at a RF power density of $67 \mathrm{~mW} / \mathrm{cm}^{2}$, the a-Si:H deposition rate starts to saturate when the $\mathrm{SiH}_{4}$ gas flow rate increases beyond $200 \mathrm{sccm}$. A very different trend in the deposition rate is observed when the RF power density is varied. There is an increase in the a-Si:H deposition rate from 71 to $91 \mathrm{~nm} / \mathrm{min}$ when the power density is increased from 67 to $100 \mathrm{~mW} / \mathrm{cm}^{2}$. The deposition rate then decreased with the further increase in the RF power density until it saturated at a significantly lower value of $67 \mathrm{~nm} / \mathrm{min}$. Further analysis of Figure 3 reveals that a sustainable increase in the a-Si:H deposition rate can be achieved through the simultaneous control of the $\mathrm{SiH}_{4}$ gas flow and the power density. In this work, we found that a $\mathrm{SiH}_{4}$ gas flow to $\mathrm{RF}$ power density ratio of around $2.4 \mathrm{sccm} / \mathrm{mW} \mathrm{cm}^{-2}$ gives a sustainable increase in the a-Si:H deposition rate. A high deposition rate of $146 \mathrm{~nm} / \mathrm{min}$ was obtained through the control of the $\mathrm{SiH}_{4}$ gas flow to RF power density ratio.

\subsection{Impact of deposition rate on thickness uniformity of the a-Si:H films over the $30 \times 40 \mathrm{~cm}^{2}$ glass}

Thickness uniformity over large areas is one of the key issues for any film deposition technique and is very critical for many semiconductor applications. The PECVD technique is renowned for its conformal deposition over large areas at low deposition rates. However, very few results are 

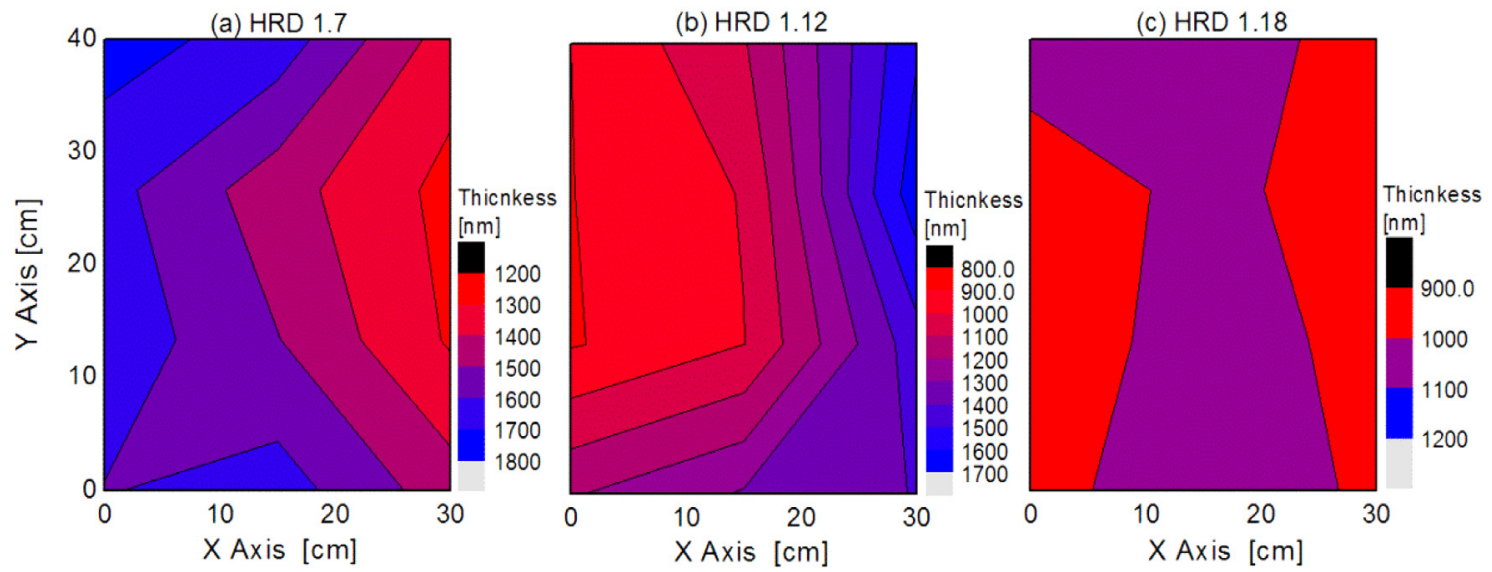

Fig. 4. Contour maps for a-Si:H thickness non-uniformity over the $30 \times 40 \mathrm{~cm}^{2}$ glass sheet at a deposition rate of (a) $75 \mathrm{~nm} / \mathrm{min}$, (b) $67 \mathrm{~nm} / \mathrm{min}$ and (c) $146 \mathrm{~nm} / \mathrm{min}$.

available in the literature for high-rate conformal PECVD deposition over large area. Thus, we further investigate the thickness uniformity of high-rate deposited a-Si:H films over the large-area $\left(30 \times 40 \mathrm{~cm}^{2}\right)$ glass sheet. The thickness non-uniformity is quantified using the following relation:

non-uniformity $\%=\left[\frac{\max _{\text {thickness }}-\min _{\text {thickness }}}{\text { max }_{\text {thickness }}+\min _{\text {thickness }}}\right] \times 100$.

Figure 4 shows the contour maps for the a-Si:H thickness non-uniformity over the $30 \times 40 \mathrm{~cm}^{2}$ glass sheet at an a$\mathrm{Si}: \mathrm{H}$ deposition rate of (a) $75 \mathrm{~nm} / \mathrm{min}$, (b) $67 \mathrm{~nm} / \mathrm{min}$ and (c) $146 \mathrm{~nm} / \mathrm{min}$. It is found that the a-Si:H films deposited at $75 \mathrm{~nm} / \mathrm{min}$ have a thickness non-uniformity of $\pm 16 \%$ over the $30 \times 40 \mathrm{~cm}^{2}$ glass sheet, whereas the aSi:H films deposited at a slightly lower deposition rate of $67 \mathrm{~nm} / \mathrm{min}$ are found to be highly non-uniform (thickness non-uniformity of $\pm 30 \%$ ). However, the a-Si:H films deposited at a very high deposition rate of $146 \mathrm{~nm} / \mathrm{min}$ are found to be highly uniform over the $30 \times 40 \mathrm{~cm}^{2}$ glass sheet, with a thickness non-uniformity value of less than $\pm 6 \%$ (see Fig. 4c). Further analysis of the thickness nonuniformity contour maps and the deposition parameters reveals that a highly uniform a-Si:H deposition is possible at high deposition rate, provided that the ratio of $\mathrm{SiH}_{4}$ gas flow rate to $\mathrm{RF}$ power density is kept at around $2.4 \mathrm{sccm} / \mathrm{mW} \mathrm{cm}^{-2}$. We also observed that $\mathrm{SiH}_{4}$ gas flow to $R F$ power density ratios of below $1.6 \mathrm{sccm} / \mathrm{mW} \mathrm{cm}^{-2}$ or above $3 \mathrm{sccm} / \mathrm{mW} \mathrm{cm}^{-2}$ lead to a very high lateral thickness variation of the a-Si:H film on the $30 \times 40 \mathrm{~cm}^{2}$ glass sheet. The samples HRD 1.7 and HRD 1.12 (see Figs. $4 \mathrm{a}$ and $4 \mathrm{~b}$ ) were obtained with a $\mathrm{SiH}_{4}$ gas flow to $\mathrm{RF}$ power density ratio of $3.3 \mathrm{sccm} / \mathrm{mW} \mathrm{cm}^{-2}$ and $1.0 \mathrm{sccm} / \mathrm{mW} \mathrm{cm}^{-2}$, respectively. A large amount thickness non-uniformity in the a-Si:H film over the large-area $\left(30 \times 40 \mathrm{~cm}^{2}\right)$ glass sheet leads to the formation of cracks during the SPC process. The cracks are mainly formed by the stress produced in the film during the heat treatment process. The large thickness variation in the a-Si:H film on the $30 \times 40 \mathrm{~cm}^{2}$ glass sheet area is one of the main causes for the stress generation. The cracks formed during the
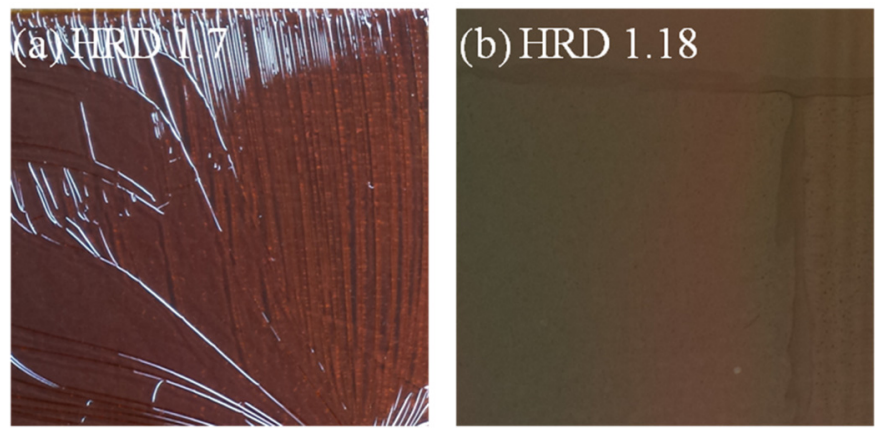

Fig. 5. Photograph of a poly-Si film obtained from SPC of a$\mathrm{Si}: \mathrm{H}$ films deposited with a $\mathrm{SiH}_{4}$ gas flow to $\mathrm{RF}$ power density ratio of (a) $3.3 \mathrm{sccm} / \mathrm{mW} \mathrm{cm}^{-2}$ and (b) $2.4 \mathrm{sccm} / \mathrm{mW} \mathrm{cm}^{-2}$.

SPC process open up during the RTA process and cover the entire film, as can be seen in Figure 5.

Figure 5 shows photographs of selected poly-Si thinfilm samples obtained from SPC of a-Si:H films deposited using a $\mathrm{SiH}_{4}$ gas flow to $\mathrm{RF}$ power density ratio of (a) $3.3 \mathrm{sccm} / \mathrm{mW} \mathrm{cm}^{-2}$ and (b) $2.4 \mathrm{sccm} / \mathrm{mW} \mathrm{cm}^{-2}$. The photos shown here were taken after the RTA process and depict a small sample area of $10 \times 10 \mathrm{~cm}^{2}$ from the centre of $30 \times 40 \mathrm{~cm}^{2}$ glass sheet. It can be clearly seen that the poly-Si film prepared from SPC of laterally highly nonuniform a-Si:H films (HRD 1.7) has cracks all over the surface (see Fig. 5a). In contrast, no cracks are observed after the RTA process for the poly-Si film obtained from SPC of a highly uniform a-Si:H film (see Fig. 5b). The high density of cracks makes the poly-Si film unsuitable for solar cell applications and thus needs to be avoided.

\subsection{Effect of deposition rate on the crystal quality of the poly-Si thin film}

The material quality of the poly-Si thin film is one of the key parameters that define its electrical properties. Thus, it is desirable to obtain a high crystal quality of the poly-Si film while trying to achieve a high-rate 


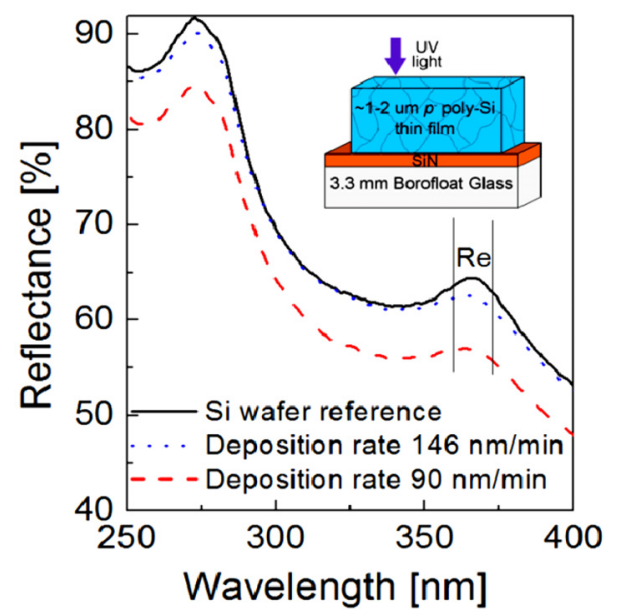

Fig. 6. Hemispherical UV reflectance measured on two polySi films obtained by SPC of a-Si:H films deposited at 90 and $146 \mathrm{~nm} / \mathrm{min}$, respectively. Also shown (solid line) is the UV reflectance measured on a polished singlecrystalline Si wafer.

deposition. Thus further investigation was undertaken to study the effect of a high deposition rate on the crystal quality, using the UV reflectance and Raman characterization techniques. Figure 6 shows the total hemispherical reflectance at short wavelengths (UV region, 250-400 nm) measured on two different poly-Si thin films prepared by $\mathrm{SPC}$ of high-rate deposited a-Si:H films, as well as on a polished FZ c-Si (100) wafer. Two characteristic peaks resulting from direct optical transitions in c-Si [19] were observed in the UV reflectance spectrum at $\sim 360 \mathrm{~nm}$ and $\sim 275 \mathrm{~nm}$ ( $R e 1$ and $R e 2)$, respectively. Structural disorder and defects in the surface region of the probed poly-Si film lead to a decrease and broadening of the peaks [20]. It can be clearly seen that the poly-Si thin film fabricated by SPC of an a-Si:H film deposited at $146 \mathrm{~nm} / \mathrm{min}$ has less structural defects than the poly-Si film fabricated by $\mathrm{SPC}$ of an a-Si:H film deposited at $90 \mathrm{~nm} / \mathrm{min}$. In addition, the reflectance spectrum obtained for the poly-Si film is quite close to that of a single-crystal Si wafer. Furthermore, the UV reflectance spectra obtained for the c-Si wafer and the poly-Si thin films were quantified in terms of the crystal quality $\left(Q_{r}\right)$ using the following relationship given in references $[14,15]$ :

$$
Q_{r}=\frac{1}{2}\left[\frac{R e 1}{R e 1 . \mathrm{c}-\mathrm{Si}}+\frac{R e 2}{R e 2 . \mathrm{c}-\mathrm{Si}}\right] .
$$

The UV-Vis-NIR measurement at wavelengths below $300 \mathrm{~nm}$ has a small signal-to-noise ratio. Therefore, we exclude the $R e 2$ to get the following equation:

$$
Q_{r}=\frac{R e 1}{R e 1 . c-S i} .
$$

The crystal quality factor $Q_{r}$ quantifies how closely the $\mathrm{UV}$ reflectance of a single-crystalline $\mathrm{Si}$ wafer is mimicked by a particular poly-Si thin-film sample and thus provides a qualitative measure of its area-averaged crystal quality [14].

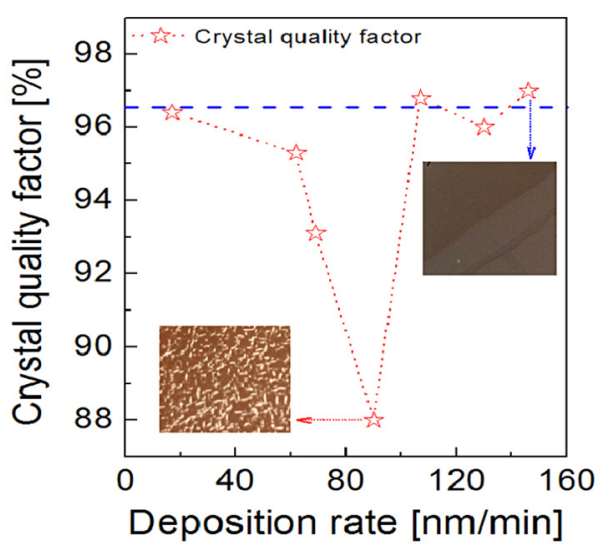

Fig. 7. Crystal quality of the SPC poly-Si thin films calculated from UV reflectance as a function of the a-Si:H deposition rate. The dotted lines are guides to the eye.

Figure 7 shows the calculated crystal quality factor for selected poly-Si thin films obtained from a-Si:H films deposited at various deposition rates. It can be clearly seen that few poly-Si thin-film samples fabricated by SPC of a$\mathrm{Si}: \mathrm{H}$ films deposited at high rate have a better UV crystal quality than those obtained from a-Si:H deposited at lower rate. Detailed analysis of the graph (see Fig. 7) and the experimental data revealed that the SPC poly-Si films with the best crystal quality were fabricated from a-Si:H films deposited using a $\mathrm{SiH}_{4}$ flow to $\mathrm{RF}$ power density ratio of about $2.4 \mathrm{sccm} / \mathrm{mW} \mathrm{cm}^{-2}$. In contrast, the SPC poly-Si films with poor crystal quality were found to be fabricated from a-Si:H films using a $\mathrm{SiH}_{4}$ gas flow to $\mathrm{RF}$ power density ratio of less than $1.6 \mathrm{sccm} / \mathrm{mW} \mathrm{cm}^{-2}$ or greater than $3 \mathrm{sccm} / \mathrm{mW} \mathrm{cm}^{-2}$. It was also observed that few of the poly-Si thin films with low UV crystal quality had an extremely high number of cracks (see Fig. 7). These cracks might have been generated during the SPC and RTA processes due to the large a-Si:H thickness variation across the large area of $30 \times 40 \mathrm{~cm}^{2}$, as discussed earlier (see Sect. 3.2). The UV reflectance merely probes the surface region ( $\sim 5 \mathrm{~nm}$ thickness) of the poly-Si film and thus the obtained UV crystal quality could just be a representation of the surface quality of the poly-Si film. The poor UV crystal quality observed in some of the poly-Si films with an extreme number of cracks could well be due to the effects of the cracks and thus does not represent the true effect of the a-Si:H deposition rate on the crystal quality of the SPC poly-Si film. Hence, selected poly-Si thin film samples were further characterised from the air side by Raman spectroscopy [16] (depth resolution $\sim 400 \mathrm{~nm}$ ), to better understand the effect of the a-Si:H deposition rate on the structural quality of the SPC poly-Si film.

Figure 8 shows Raman spectra acquired from the visible $(532 \mathrm{~nm})$ laser line for selected poly-Si thin films fabricated by SPC of a-Si:H films deposited at 17 and $146 \mathrm{~nm} / \mathrm{min}$. As a reference, the Raman spectrum was also obtained for a single-crystal high-resistivity FZ Si (100) wafer (solid line). A strong peak at a frequency $\omega_{0}$ of about $522 \mathrm{~cm}^{-1}$ is observed for the c-Si wafer. This peak position value of c-Si may slightly vary from experiment to 


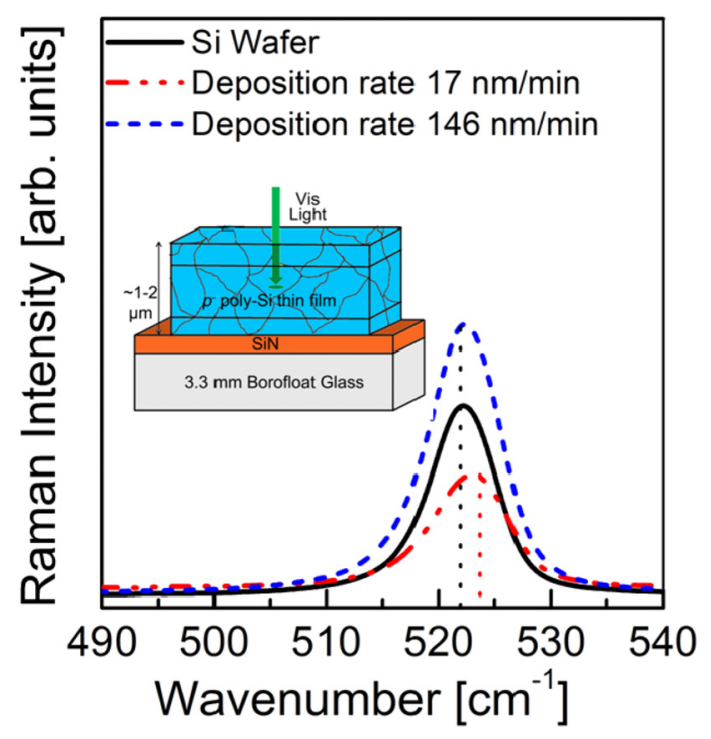

Fig. 8. Raman spectra of poly-Si films deposited at two different deposition rates of 17 and $146 \mathrm{~nm} / \mathrm{min}$, respectively. Also shown (solid line) for comparison is the Raman spectrum measured on a polished single-crystal Si wafer.

experiment, depending on the calibration of the spectrometer and monochromator. Furthermore,the Raman spectra for poly-Si film obtained from SPC of a-Si:H films deposited at $17 \mathrm{~nm} / \mathrm{min}$ reveal that there is a shift in the peak position towards higher wave numbers with respect to $\mathrm{c}-\mathrm{Si}$, indicating the presence of compressive stress in the poly-Si film [21]. However, it is worth to note that the poly-Si film fabricated by SPC of a-Si:H deposited at a high deposition rate of $146 \mathrm{~nm} / \mathrm{min}$ is found to have no stress in the film.

From the analysis of the Raman spectra and the process parameters revealed that stress in the SPC poly-Si film can be reduced by the control of the $\mathrm{SiH}_{4}$ gas flow to RF power density ratio. Furthermore, the Raman spectra reveal that the full width at half maximum (FWHM) of the poly-Si thin films varies with the deposition rate of the a-Si:H film. The FWHM is an excellent indicator of the crystal quality of the poly-Si film. An increase in the defect density and disorder in Si thin films leads to a broadening of the peak (FWHM) $[16,22,23]$. A Raman quality factor $\left(R_{Q}\right)$ is defined here as the ratio between the FWHM of single-crystal Si to that of the poly-Si film $\left(R_{Q}=\frac{F W H M_{c-S i}}{F W H M_{\text {poly-Si }}}\right)$ to quantify the defects in the poly-Si film relative to a (stress-free) single-crystal Si wafer.

Figure 9 shows the calculated Raman quality factor of the poly-Si thin film obtained by SPC of a-Si:H films as a function of the deposition rate. It can be clearly seen that few poly-Si films obtained by SPC of a-Si:H films deposited at higher rate had better crystal quality than those obtained from a-Si:H deposited at low deposition rate. The interpretation of poly-Si thin film crystal quality obtained from Raman measurements is in good agreement with the crystal quality factor obtained from UV reflectance measurements for most of the poly-Si thin film reported here.

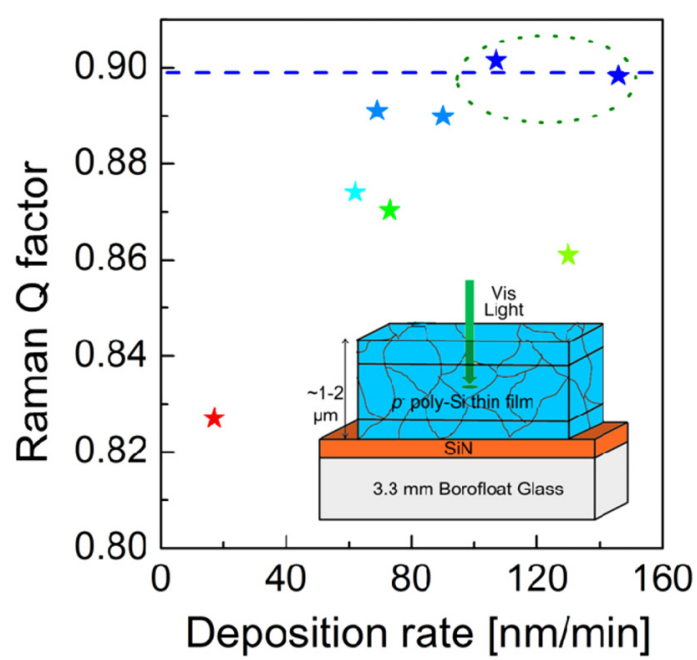

Fig. 9. Raman quality factor $\left(R_{Q}\right)$ of SPC poly-Si thin films as a function of the a-Si:H deposition rate.

\section{Conclusion}

In conclusion, a high deposition rate of $146 \mathrm{~nm} / \mathrm{min}$ was achieved through the control of the $\mathrm{SiH}_{4}$ gas flow and the RF power density. A laterally highly uniform deposition of a-Si:H over the large glass sheet area of $1200 \mathrm{~cm}^{2}$ using high-rate PECVD was achieved. A relationship between the $\mathrm{SiH}_{4}$ gas flow and the $\mathrm{RF}$ power density was established. A linear increase in the deposition rate up to $146 \mathrm{~nm} / \mathrm{min}$ was achieved by keeping the $\mathrm{SiH}_{4}$ gas flow to $\mathrm{RF}$ power density ratio constant at about $2.4 \mathrm{sccm} / \mathrm{mW} \mathrm{cm}^{-2}$. The $\mathrm{SiH}_{4}$ gas flow to RF power density ratio was also found to affect the thickness uniformity of a-Si:H films and the material quality of the SPC polySi films obtained from the a-Si:H films. A very high SPC poly-Si crystal quality with a thickness non-uniformity of less than $\pm 6 \%$ over $30 \times 40 \mathrm{~cm}^{2}$ was obtained. A further increase in the deposition rate to about $250 \mathrm{~nm} / \mathrm{min}$ seems possible through the control of the $\mathrm{SiH}_{4}$ gas flow and the RF power density, while maintaining good thickness uniformity and a high crystal quality.

The Solar Energy Research Institute of Singapore (SERIS) is sponsored by the National University of Singapore (NUS) and the National Research Foundation (NRF) of Singapore through the Singapore Economic Development Board (EDB). This research was supported by the NRF, Prime Minister's Office, Singapore under its Clean Energy Research Programme (Award No. NRF2009EWT-CERP001-046). A.K. acknowledges Ph.D. scholarships from Singapore's Energy Innovation Programme Office.

\section{References}

1. A.G. Aberle, Thin Solid Films, 517, 4706 (2009)

2. A. Kumar, P.I. Widenborg, H. Hidayat, Q. Zixuan, A.G. Aberle, in MRS Proceedings, 2011, Vol. 1321 
3. P.A. Basore, in Proceedings of the 4 th World Conference on Photovoltaic Energy Conversion, Hawaii, 2006, pp. $874-876$

4. Z. Ouyang, O. Kunz, M. Wolf, P. Widenborg, G. Jin, S. Varlamov, in 18th International Photovoltaic Science and Engineering Conference, Kolkata, 2009, p. 023

5. D.L. Young, P. Stradins, Y. Xu, L. Gedvilas, B. Reedy, A.H. Mahan, H.M. Branz, Q. Wang, D.L. Williamson, Appl. Phys. Lett. 89, 122103 (2006)

6. T. Takagi, K. Takechi, Y. Nakagawa, Y. Watabe, S. Nishida, Vacuum 51, 751 (1998)

7. T. Takagi, R. Hayashi, G. Ganguly, M. Kondo, A Matsuda, Thin Solid Films 345, 75 (1999)

8. V. Kirbs, T. Drusedau, H. Fiedler, J. Phys.: Condens. Matter 4, 10433 (1992)

9. M. Estrada, A. Cerdeira, I. Pereyra, S. Soto, Thin Solid Films 373, 176 (2000)

10. B.A. Korevaar, G.J. Adriaenssens, A.H.M. Smets, W.M.M. Kessels, H.Z. Song, M.C.M. van de Sanden, D.C. Schram, J. Non-Cryst. Solids 266-269, 380 (2000)

11. J. Hautala, Z. Saleh, J.F.M. Westendorp, H. Meiling, S. Sherman, S. Wagner, in MRS Proceedings, 1996, Vol. 420

12. G. Jin, Ph.D. Thesis, The University of New South Wales, 2010

13. G. Harbeke, L. Jastrzebski, J. Electrochem. Soc. 137, 696 (1990)
14. A. Straub, P.I. Widenborg, A. Sproul, Y. Huang, N.P. Harder, A.G. Aberle, J. Cryst. Growth 265, 168 (2004)

15. P.I. Widenborg, A.G. Aberle, J. Cryst. Growth 306, 177 (2007)

16. S. Nakashima, M. Hangyo, IEEE J. Quantum Electron. 25, 965 (1989)

17. M. Holtz, W.M. Duncan, S. Zollner, R. Liu, J. Appl. Phys. 88, $2523(2000)$

18. G. Bruno, P. Capezzuto, G. Cicala, Chemistry of Amorphous Silicon Deposition Processes: Fundamentals and Controversial Aspects, in: Plasma Deposition of Amorphous Silicon-Based Materials, edited by G. Bruno, P. Capezzuto, A. Madan (Academic Press, San Diego, 1995), pp. 1-62.

19. P.Y. Yu, M. Cardona, Fundamentals of semiconductors: physics and materials properties (Springer, Berlin, 1999)

20. T. Kamins, Polycrystalline silicon for integrated circuit applications (Kluwer Academic Publishers, 1988)

21. K. Kitahara, A. Hara, in Crystallization - Science and Technology, edited by M.R.B. Andreka (Intech, Rijeka, 2012)

22. A. Kumar, H. Hidayat, C. Ke, S. Chakraborty, G.K. Dalapati, P.I. Widenborg, C.C. Tan, S. Dolmanan, A.G. Aberle, J. Appl. Phys. 114, 134505 (2013)

23. R.C. Teixeira, I. Doi, M.B.P. Zakia, J.A. Diniz, J.W. Swart, Mater. Sci. Eng. B 112, 160 (2004)

Cite this article as: Avishek Kumar, Per Ingemar Widenborg, Goutam Kumar Dalapati, Gomathy Sandhya Subramanian, Armin Gerhard Aberle, Impact of deposition parameters on the material quality of SPC poly-Si thin films using high-rate PECVD of a-Si:H, EPJ Photovoltaics 6, 65303 (2015). 